\title{
PODERES SINDICAIS EM (RE)CONSTRUÇÃO? ILAÇÕES SETORIAIS NO CONTEXTO PORTUGUÊS1
}

\section{TRADE UNION POWERS UNDER (RE)CONSTRUCTION? SECTORIAL LESSONS IN THE PORTUGUESE CONTEXT}

\author{
Hermes Augusto Costa \\ Faculdade de Economia, Universidade de Coimbra \& Centro de Estudos Sociais. Avenida Dias da Silva, 165, \\ 3004-512 Coimbra, Portugal. Email: hermes@fe.uc.pt
}

\author{
Elísio Estanque \\ Faculdade de Economia, Universidade de Coimbra \& Centro de Estudos Sociais. Avenida Dias da Silva, 165, \\ 3004-512 Coimbra, Portugal. Email: elisio.estanque@gmail.com
}

\section{Dora Fonseca}

Centro de Estudos Sociais \& Universidade de Coimbra. Avenida Dias da Silva, 165, 3004-512 Coimbra, Portugal. Email: dorajfonseca@ces.uc.pt

\begin{abstract}
Resumo: Ao longo das últimas décadas tornou-se frequente reconhecer que o sindicalismo entrou em "derrapagem", mormente de perda de associados. A expressão dessa realidade objetiva é indissociável de uma perceção mais ampla de perda de poder. Torna-se, pois, necessário recuperar alguns debates sobre as formas de poder sindical (estrutural, organizacional/associativo, institucional, societal) trabalhadas na literatura internacional e de os situar no contexto português. Nesse sentido, tendo por base uma investigação empírica realizada em três setores de atividade (metalúrgico, transportes e telecomunicações) e três empresas de referência (Autoeuropa, TAP e PT/ Altice), procede-se a um levantamento das possibilidades de afirmação do sindicalismo nos setores estudados (e por sinal sujeitos a transformações e restruturações, em especial no quadro da "era de austeridade"). A partir de uma análise combinada de seis critérios - representatividade; qualificação; conflito/negociação; nacional/internacional; público/privado; inovação - , constatou-se uma evolução assimétrica dos recursos de poder, tanto no que se refere à relação dos vários tipos de poder entre si, como na forma como evoluíram consoante o setor de atividade. Em decorrência do contexto de austeridade, algumas formas de poder (associativo e, sobretudo, societal) apresentaram sinais de recuperação, enquanto outras formas de poder (estrutural e institucional) evidenciaram sinais de maior fraqueza.
\end{abstract}

Palavras-chave: sindicalismo, formas de poder, setores metalúrgico, dos transportes e das telecomunicações, Portugal.

\begin{abstract}
Over the last decades, it has become increasingly recognized that trade unionism has gone into crisis, particularly of membership loss. The expression of this objective reality is inseparable from a broader perception of power loss. It is therefore necessary, from the outset, to retrieve some debates about the forms of trade union power (structural, organizational/associative, institutional, societal) analysed in the international literature and situating them in the Portuguese context. In this sense, based on an empirical investigation carried out in three sectors of activity (metallurgical, transport and telecommunications) and three reference companies (Autoeuropa, TAP and PT/Altice), the possibilities of trade unionism affirmation in these sectors ( subject to transformations and restructuring, especially in the framework of the "age of austerity") are surveyed. From a combined analysis of six criteria
\end{abstract}


- representativeness; qualification; conflict / negotiation; national/international; public/private; innovation - , an asymmetric evolution of power resources has been found, both in what regards the relationship between the various types of power and how they have evolved according to the sector of activity. As a result of the austerity context, some forms of power (associative and, above all, societal) showed signs of recovery, while other forms of power (structural and institutional) showed signs of greater weakness.

Keywords: trade unionism, forms of power, metallurgical, transport and telecommunications sectors, Portugal.

\section{Introdução}

Durante as últimas décadas tornou-se comum reconhecer que o sindicalismo entrou em "derrapagem", muito em resultado da perda de associados (a crise de representatividade), mas também da perda de autonomia, da escassez de internacionalização ou défice de alianças sociais (Costa, 2018; Estanque, Costa e Silva, 2015). À expressão dessa realidade objetiva subjaz um inevitável questionamento das possibilidades de reafirmação sindical no contexto atual.

Qualquer exercício que vise empreender uma discussão crítica sobre o património histórico do sindicalismo e as possibilidades de revitalização constitui, em si mesmo, um convite ao debate sobre o "poder sindical". Trata-se de um debate ou melhor, de um conjunto de debates - que se articula diretamente com a temática da revitalização. Especialmente tendo presentes as enormes transformações operadas no mercado de trabalho em resultado das medidas prescritas pelo Memorando de Entendimento do período da austeridade (em particular, entre 2011 e 2015) e do processo de "desvalorização interna" (Silva, Hespanha e Caldas, 2017), assume-se como vital o enfoque sobre as orientações e práticas sindicais, no sentido de percecionar o alcance da sua revitalização.

Obedecendo ao objetivo mais geral de apresentar evidências empíricas que possam contrariar as visões mais pessimistas de refluxo total do movimento sindical, especialmente durante o período mais crítico da intervenção externa em Portugal, neste trabalho procuramos dar visibilidade a experiências concretas de atividade sindical que denotam obstáculos, mas também sinais de "abertura" e (re)afirmação. Este trabalho pretende, assim, articular essas experiências com o quadro teórico dos recursos de poder sindical, o qual reúne contributos de inegável interesse analítico para a compreensão das dinâmicas sindicais contemporâneas.

Este texto encontra-se, assim, dividido em três partes. Na primeira, recuperamos a literatura relevante sobre os "recursos de poder", onde se destacam as formas de poder através das quais os sindicatos podem fazer a diferença na sociedade: 
estrutural, associativo/organizacional, institucional e societal. Em articulação com essa literatura, não deixamos também de mobilizar o célebre contributo de Richard Hyman (2001), assente no triângulo analítico "mercado, classe e sociedade", que nos alerta para as distintas possibilidades de atuação sindical que se jogam nas arestas daquele triângulo. Na segunda parte, apresentam-se as linhas orientadoras de um projeto de investigação concluído em 2019 - Rebuilding trade union power under austerity age: Three sectors under review - eque incidiu em três empresas de referência no contexto português (a Autoeuropa, a TAP-Air Portugal e a Portugal Telecom/Altice, atual Altice Portugal) e em três setores de atividade (metalúrgico, dos transportes e das telecomunicações). O objetivo é o de expor os eixos analíticos subjacentes à investigação realizada e suscitar o cruzamento entre tais eixos e as formas de poder sindical. Sequencialmente, procede-se à conjugação da análise setorial e dos critérios analíticos, fazendo-os convergir para os três estudos de caso mencionados. Por um lado, as empresas selecionadas ocupam uma posição estratégica em termos de mercado, concentrando poder económico e de influência, o que claramente destoa de um tecido empresarial predominantemente composto por pequenas e médias empresas. Por outro, nos casos da Autoeuropa e da TAP, estamos diante de empresas que, na prática, funcionam como subsetores de atividade (automóvel e aviação) dos setores (metalúrgico e dos transportes) em que, respetivamente, se inserem. Tal obriga, pois, a reconhecer que é necessária alguma prudência nas análises e interpretações produzidas de modo a evitar excesso de generalizações. Não obstante, é nossa convicção que as pistas daí emergentes possam contribuir significativamente para a reflexão e investigação em torno da temática dos recursos de poder e sua articulação com os processos de revitalização sindical.

Assim, na derradeira secção são apresentados alguns resultados que permitem tirar ilações sobre os processos de reconstrução do poder sindical nas suas várias vertentes.

\section{Recursos de poder em debate}

A perceção contemporânea da relevância social do sindicalismo tem recebido uma multiplicidade de contributos, ainda que, em nosso entender, um dos mais relevantes tenha sido o de Richard Hyman. Ao propor uma conceção dos sindicatos enquanto "mercado, classe e sociedade", este autor estabeleceu três tipos ideais de sindicalismo europeu associados a ideologias, identidades e estratégias sindicais distintas (Hyman, 2001, pp. 1-4). Na prática, como é salientado por Hyman, estas não se apresentam sob formas totalmente "puras", podendo aqueles elementos assumir formas "mistas" em formações históricas concretas e setores específicos. 
Não raramente ocorrem reorientações, principalmente em momentos e épocas que colocam desafios acrescidos às organizações sindicais. Nessa medida, atribui às ideologias, identidades, e formas de organização sindical um caráter dinâmico. No modelo triangular que propõe, o vértice "mercado" corresponde a uma conceção dos sindicatos como organizações de interesses no âmbito do mercado de trabalho, que assumem como foco a sua regulação com vista a melhorar a posição económica e social dos trabalhadores, salientando, portanto, os mecanismos de negociação coletiva como meio para o conseguir. Ainda que em âmbito mais restrito, o business unionism americano pode ser identificado com essa visão dos sindicatos como atores de "mercado". Conotado com categorias de trabalhadores relativamente qualificadas e com as ocupações de ofício, aponta para uma visão dos sindicatos enquanto atores económicos (Hyman, 2001, pp. 8-9), guiados por objetivos pragmáticos: satisfazer interesses económicos concretos dos trabalhadores no emprego, no contexto da produção industrial; negociação coletiva como via para obter melhores condições de trabalho; mais "consciência do emprego" em vez de "consciência de classe" (Larson e Nissen, 1987, p. 131; Paquet, Tremblay e Gosselin, 2004, p. 302).

De um lado oposto a esta visão de "mercado", o legado marxista deu corpo à conceção do sindicalismo enquanto agente de "classe", onde a ênfase no conflito estruturado em torno da relação entre capital e trabalho, na luta social, se impôs associada à ideia dos sindicatos como "escolas de guerra" - , ainda que as visões pluralistas (não exclusivamente marxistas) também aí tivessem um ponto de ancoragem. O contexto de austeridade vivido em Portugal (sobretudo na $1^{\mathrm{a}}$ metade da presente década) é um bom exemplo do espaço de combatividade que se abriu e que teve nas organizações sindicais (e ainda em outros atores sociolaborais) protagonistas centrais.

Por fim, a referência à "sociedade" associada ao sindicalismo veio colocar em primeiro plano a valorização do diálogo social e a necessidade de consolidar a atuação sindical no quadro de estratégias de parceria social mais amplas (com governos, empregadores ou organizações não sindicais). Esta perceção do sindicalismo enquanto "veículo de integração social" (Hyman, 2001, p. 2) encontra-se, pois, direcionada para a promoção do sentido de justiça social.

Ora, a análise de Hyman é útil, desde logo, porque se conjugada com a literatura dos recursos de poder, permite alertar para as possibilidades de (re)afirmação sindical - seja como classe, mercado ou sociedade - que se articulam em vários domínios de forma distinta e ampliada. Tendo por inspiração a trilogia de Hyman, que recursos de poder estão, então, em jogo? A temática dos recursos de poder tem suscitado várias abordagens, merecendo destaque, por exemplo, as produzidas por Visser (1995) ou por Jensen, Madsen e Due (1995). A primeira aponta para 
importantes focos de potencial poder sindical, tais como a mobilização e recrutamento, os processos de diálogo/consulta com associações de empregadores e entidades públicas, ou o padrão de qualificações dos filiados num sindicato como influenciador da sua posição no mercado laboral. Já a segunda alude à (sempre latente) capacidade conflitual dos sindicatos ou de pressão sobre o poder político. Alguns estudos posteriores (Crouch, 2017; Gumbrell-McCormick e Hyman, 2013; McGuire, 2014; Schmalz e Dörre, 2013; Silver, 2003; Wright, 2000) reformularam essas análises, atualizando-as e aprofundando-as.

Uma síntese dessas análises sobre os recursos de poder pode encontrar-se em Lehndorff, Dribbush e Schulten (2017), autores que destacam as seguintes formas de poder sindical: estrutural, associativo/organizacional, institucional e societal. O poder estrutural reside na posição ocupada pelos trabalhadores no mercado de trabalho (ditado pela escassez de trabalhadores) e no processo de trabalho (resultante da localização dos trabalhadores). Tal forma de poder será tanto maior quanto mais difícil for substituir trabalhadores em virtude das suas qualificações e posição na cadeia de valor. Isto significa que falamos de uma forma de poder sindical diretamente talhada pelo modelo particular de desenvolvimento socioeconómico nacional, bem como pela política social e económica e estratégias dos empregadores na restruturação das cadeias de valor e processos de trabalho.

Por sua vez, o poder organizacional/associativo prende-se com a capacidade de mobilização da filiação que, antes de mais, depende essencialmente dos próprios sindicatos. Existe, assim, uma influência recíproca entre a dimensão da filiação sindical e a capacidade de financiamento dos sindicatos. Enquanto em alguns países o poder organizacional depende das contribuições financeiras resultantes da filiação, noutros os contributos (diretos ou indiretos) podem resultar da negociação de convenções coletivas ou da legislação.

A legislação laboral, as estruturas representativas dos trabalhadores nas empresas ou a negociação de convenções coletivas são aspetos que reforçam uma outra fonte de poder sindical: o poder institucional (Dörre, 2017; Schmalz e Thiel, 2017). Com efeito, esta forma de poder decorre da capacidade dos sindicatos organizarem e representarem trabalhadores, mas igualmente da sua posição na negociação coletiva ou participação nas instâncias de concertação social (Campos Lima e Martin Artiles, 2011). Tratando-se de uma forma de poder suscetível de influenciar a atuação dos atores políticos e que é sensível à intervenção legislativa, pode ser explorada pelos sindicatos mesmo em momentos de declínio do poder organizacional/associativo ou do poder estrutural.

O último tipo foi particularmente afetado pelas imposições decorrentes da aplicação do Memorando de Entendimento. As alterações à legislação laboral materializadas 
na Lei 23/2012, nomeadamente as relativas ao tempo de trabalho e à remuneração do trabalho extraordinário, bem como a questão da caducidade das convenções coletivas e os novos critérios de extensão, coartaram o poder institucional dos sindicatos de forma bem visível, acabando por ter um efeito contrário ao pretendido - a resolução de bloqueios existentes - e exacerbar os níveis de conflito (ILO, 2018). Aliás, a extensão dessas medidas após 2014 foi considerada uma violação do princípio da autonomia da negociação coletiva pelo Tribunal Constitucional. No entanto, é necessário frisar que as reformas do mercado de trabalho sob a égide do Memorando de Entendimento surgem em continuidade com importantes alterações à legislação laboral que vinham tendo lugar desde 2003, além de muitas das medidas serem já incluídas no Acordo Tripartido para a Competitividade e o Emprego assinado em março de 2011, precedendo assim o pedido de assistência financeira (Campos Lima, 2017; Távora e González, 2016).

O poder societal corresponde às latitudes para a ação que emergem a partir de contextos viáveis de cooperação com outros grupos sociais e organizações. Além disso, nessa forma de poder também se incorpora o apoio da sociedade às reivindicações sindicais, no sentido da generalização do projeto político do sindicato e sua adoção pela sociedade, o que pressupõe a abertura do ambiente social dos sindicatos (Schmalz e Dörre, 2013). Compreende uma componente colaborativa (traduzida na capacidade de os sindicatos construírem coligações no âmbito de redes na sociedade civil, inclusive com partidos políticos e movimentos sociais, e de as ativarem no contexto de mobilizações e campanhas), bem como uma componente discursiva e comunicativa (expressa na capacidade de os sindicatos fornecerem padrões de interpretação - framing - , influenciarem o discurso público e fixarem uma agenda).

Tal como os vértices do triângulo "mercado-classe-sociedade", as várias formas de poder não se encontram isoladas, podendo interagir e compensar-se mutuamente, o que significa que os recursos de poder dos sindicatos funcionam de forma dinâmica. Colocar como horizonte desejável a revitalização sindical significa, na perspetiva adotada neste trabalho, colocar o enfoque sobre os recursos de poder que os sindicatos têm à sua disposição. Seguindo a premissa do dinamismo do funcionamento dos recursos de poder como um todo ao nível de dimensões distintas, é possível argumentar, na linha de Behrens, Hamann e Hurd (2004), que a revitalização sindical é um processo multidimensional ${ }^{2}$ e situado contextualmente, que pode ser concebido como forma de (re)conquistar poder no âmbito das várias dimensões envolvidas na atividade sindical. Na medida em que os esforços de revitalização sindical podem focar-se numa dimensão ou na combinação de várias, os recursos de poder sindical funcionam de forma integrada. 


\section{Uma proposta analítica para o estudo da (re)afirmação sindical em três setores}

No âmbito do já citado projeto de investigação, foram propostos e testados 6 critérios de análise como forma de captar os principais espaços onde o sindicalismo poderá estar a recuperar poder: representatividade; qualificação; conflito/negociação; nacional/internacional; público/privado; e inovação. Cada um desses critérios - que não podem ser analisados de forma autónoma, desenvolvendo ligações entre si foi, entretanto, cruzado com os recursos de poder anteriormente apresentados, bem como com dois níveis de análise: o nível setorial (designadamente os setores metalúrgico, dos transportes e das telecomunicações); e o nível da empresa, pois tratou-se de perscrutar os rumos das organizações sindicais a partir de três empresas de referência no panorama empresarial português (como já se disse, concedeu-se um destaque especial aos estudos de caso na Autoeuropa, na TAP-Air Portugal e na Portugal Telecom/Altice). O trabalho empírico assentou sobretudo na realização de entrevistas e focus groups junto de representantes sindicais daqueles setores, bem como de outras organizações representativas de trabalhadores ${ }^{3}$.

Através do critério representatividade procurou-se ir ao encontro de uma expressão quantitativa ("quantos são os filiados?"), a qual implicava auscultar o perfil social dos membros do sindicato, permitindo também dialogar com o critério qualificação. Assim, se por um lado se procurou atualizar os índices e tendências da sindicalização (o que não deixou de se revestir de dificuldades) e perceber as razões associadas à perda de associados ou as estratégias acionadas para a recuperação do número de sócios, por outro, indagou-se sobre o perfil sociodemográfico dos membros do sindicato (idade, género, qualificações) e sobre os níveis de formação e as qualificações dos trabalhadores do setor em análise. Ao serem convocados estes dois primeiros critérios, foram igualmente postos à prova duas formas de poder: poder organizacional/associativo e poder estrutural.

Um terceiro critério estudado foi o binómio conflito/negociação. Como é sabido, ambas as vertentes são inerentes ao movimento sindical desde o seu nascimento no século XIX. Através deste critério, os vários interlocutores foram confrontados com os impactos negativos sobre a vida dos trabalhadores (nomeadamente em termos contratuais, salariais, e de proteção no desemprego) decorrentes quer das alterações da legislação laboral, quer do Memorando da troika na sua globalidade. Como é salientado por Campos Lima (2017), as alterações às normas relativas à vigência e caducidade e à extensão das convenções coletivas, e a reversão do princípio favor laboratoris, bem como outras medidas no sentido da descentralização do sistema de negociação coletiva, inscreveram-se na lógica da desvalorização interna e do ajustamento rápido às flutuações do mercado. A “descentralização organizada" cumpriria 
o objetivo de facilitar a almejada flexibilidade e o alinhamento dos salários com a produtividade das empresas (Távora e González, 2016). Contudo, essa descentralização foi sobretudo "desorganizada" (Campos Lima, 2017). São também de salientar as alterações no sentido de fazer depender a extensão das convenções coletivas da representatividade das partes. Uma consequência clara da supressão dos mecanismos de extensão e da reversão do princípio da favorabilidade residiu na impossibilidade dos sindicatos se apoiarem nesses mecanismos como forma de reequilibrarem a estrutura da negociação (Koukiadaki, Távora e Martínez Lucio, 2016). Assim, por um lado, no campo do conflito, tratou-se de procurar perceber, entre outros pontos: qual a expressão do conflito naquela empresa e setor nos últimos anos; as motivações associadas às lutas; possíveis inflexões ou recrudescimentos; o peso atribuído às manifestações e greves como estratégia do sindicato; e os ganhos decorrentes de uma ação coletiva conflitual. Por outro, no vetor da negociação, interessava-nos perceber a relevância das convenções coletivas celebradas por cada sindicato entre 2008 e 2013 e de 2013 até ao presente. Em especial, de modo a identificar os principais conteúdos das convenções, as dificuldades associadas a tais processos, a sua aplicabilidade e resultados obtidos. E ainda que quer o conflito quer a negociação se joguem sobretudo na relação entre capital-trabalho, a relação entre organizações sindicais filiadas em diferentes estruturas (CGTP ou UGT) ou entre sindicatos e comissões de trabalhadores esteve também presente nas interações com os interlocutores. No que diz respeito à interface entre este critério e as formas de poder, emergiram ilações quer sobre o poder estrutural, quer sobre o poder institucional.

Outro critério valorizado na nossa análise foi o binómio nacional/internacional. Tratou-se aqui de medir o peso relativo das apostas internas e externas. As primeiras dizem mais diretamente respeito à identificação das principais preocupações do sindicato em termos de condições de trabalho e de política salarial, tentando perceber quais foram as campanhas implementadas no período mais recente. As segundas remetem para desafios vários no plano europeu/internacional (filiação em estruturas sindicais transnacionais; participação em campanhas internacionais e ações de solidariedade; envolvimento em conselhos de empresa europeus, acordos-quadro globais ou conselhos sindicais inter-regionais). Este critério suscita pistas de análise que interferem mais diretamente com o poder societal, ainda que não de modo exclusivo.

A relação entre público/privado foi também tomada como critério de análise. Ora, estando o estudo centrado em empresas que foram alvo de processos de (re)privatização (como a TAP e a PT/ Altice), não poderíamos deixar de indagar, desde logo, quais os efeitos da privatização sobre o número de sindicalizados e sobre a ação e estratégias sindicais, e também em termos salariais. Por outro lado, 
tornava-se importante questionar em que medida a privatização conduziu a uma maior flexibilidade contratual e de horários e quais as posições e ações levadas a cabo pelos sindicatos relativamente a esses aspetos. Simultaneamente, afigurava-se curial apurar em que medida a privatização conduziu à adoção de novas estratégias de gestão da empresa e de que modo produziu efeitos nos instrumentos de regulamentação coletiva e nos processos negociais (sendo neste ponto evidentes as conexões com o critério conflito/negociação). Este critério articula-se quer com o poder associativo/organizacional, quer com o poder institucional.

Por fim, o sexto critério de análise diz respeito à inovação. Este é um critério suficientemente amplo para suscitar uma diversidade de leituras e interpretações. Por um lado, interessou-nos auscultar em que medida, na sequência do período de contração da economia, a empresa apostou na inovação - tanto ao nível da gestão como do processo produtivo, como forma de alavancar a recuperação e o crescimento - e até que ponto o sindicato foi consultado quanto à introdução de novas técnicas e processos. Aliás, ante uma eventual introdução de processos de inovação, tratou-se também de averiguar se as necessidades dos trabalhadores (em termos de formação, por exemplo) foram acauteladas e qual a posição formulada pelo sindicato relativamente a essa questão. Por outro lado, além de um registo reativo face à atuação da empresa, interessou-nos, neste critério, perceber até que ponto é possível falar, de uma forma proativa, em inovação no interior do próprio sindicato. Ou seja, apurar em que medida têm ocorrido mudanças na estrutura sindical, tendo em vista uma certa "modernização" e "atualização" (rearranjo das estruturas sindicais e práticas organizacionais, renovação dos reportórios de ação coletiva, aproximação entre insiders e outsiders). E outra matéria conexa com esta prende-se com a perceção dos responsáveis sindicais sobre se a introdução de novas tecnologias como forma de comunicação do sindicato tem vindo a crescer, tanto no seu interior como com o exterior, e sobretudo se as novas tecnologias estão a constituir-se como uma forma importante de captar novos membros. O papel do Facebook e os seus resultados práticos foi outro aspeto que procurámos indagar. E, por fim, se o critério inovação não deveria também materializar-se na aproximação do sindicalismo a outros públicos não sindicais. Quanto à interface com os recursos de poder, este critério dialoga preferencialmente com o poder associativo/organizacional, mas igualmente com o poder societal. Aliás, a necessidade de captação de outros públicos pressupõe em si mesma uma maior abertura à sociedade que, como sugerido, é em grande parte mediada pela inovação nas formas de comunicação e de organização sindicais.

O quadro que se segue ilustra alguns dos possíveis cruzamentos/sobreposições entre os recursos de poder sindical e os critérios analíticos contemplados neste estudo. 
Tabela 1 Articulação dos recursos de poder sindical com os critérios analíticos

\begin{tabular}{l|c|c|c|c|c|c}
\hline & \multicolumn{5}{c}{ Critérios } \\
\cline { 2 - 7 } Recursos & Representatividade & Qualificação & $\begin{array}{c}\text { Conflito / } \\
\text { Negociação }\end{array}$ & $\begin{array}{c}\text { Nacional / } \\
\text { Internacional }\end{array}$ & $\begin{array}{c}\text { Público / } \\
\text { Privado }\end{array}$ & Inovação \\
\hline Poder Estrutural & & $X$ & $X$ & & & \\
Poder Associativo & $X$ & $X$ & & $X$ & $X$ \\
Poder Institucional & & & $X$ & $X$ & $X$ & $X$ \\
Poder Societal & & & & $X$ & & $X$ \\
\hline
\end{tabular}

Como já se mencionou, a repartição dos critérios analíticos foi igualmente articulada com os setores e estudos de caso. Assim, ao setor metalúrgico (mais próximo da conceção de "sindicalismo de classe", tendo em conta a prevalência do conflito estruturado em torno da relação entre capital e trabalho) fizemos corresponder o estudo de caso da Autoeuropa, destacando nele os critérios conflito/negociação (bem expresso, de resto, nas tensões suscitadas desde julho de 2017 a propósito da organização do tempo de trabalho), nacional/internacional e ainda o critério "qualificação" (dada a sua relevância em termos de poder estrutural, que, como vimos, decorre da posição dos trabalhadores quer no mercado de trabalho quer no processo de trabalho). Por sua vez, ao setor dos transportes (em que as estratégias sindicais valorizam, de um modo geral, o diálogo social e as práticas de parceria), mais condizente com o vértice "sociedade" do modelo de Hyman, fizemos corresponder o estudo de caso da TAP-Air Portugal e, dentro dele, destacámos, além dos critérios conflito/negociação e nacional/internacional, o critério público/privado. Por fim, ao setor das telecomunicações - identificado com o vértice "mercado" do modelo, tendo em conta a prevalência de estratégias sindicais centradas na promoção das condições sociais e económicas dos trabalhadores - fizemos corresponder o estudo de caso da PT / Altice, realçando nele os critérios público/privado, nacional/internacional e ainda o critério "qualificação".

\section{Alguns resultados da investigação}

Nesta secção pretende-se explorar o comportamento dos seis critérios analíticos subjacentes à investigação realizada. O critério público/privado é articulado com os restantes critérios nos estudos de caso da PT/Altice e TAP, enquanto as implicações do critério qualificação são transversais aos demais critérios, pelo que optámos por não proceder à apresentação de forma tão circunstanciada e autonomizada dos resultados encontrados para aqueles critérios. 


\section{Representatividade}

No que diz respeito ao critério representatividade, constatou-se, nos três setores em análise, que a evolução da sua expressão quantitativa não corresponde à perceção difundida da tendência de perda de membros ou, por outro lado, de incapacidade de captação de novos membros. E mesmo que o período da austeridade durante o qual o Memorando de Entendimento impôs medidas de ajustamento fiscal-estrutural, bem como alterações à legislação laboral que colocaram constrangimentos às empresas de uma forma geral e às aqui visadas em particular - tenha acarretado em primeira instância, como é comumente reconhecido, uma quebra da filiação, a forma como isso se reflete em cada um dos três setores difere e é mediada por circunstâncias específicas, podendo inclusive variar quando o foco da análise é fixado ao nível das empresas tomadas como estudos de caso.

Começando pelo setor metalúrgico, o panorama geral aponta para uma quebra da sindicalização durante o período da intervenção da Troika, muito embora a mesma tenha sido de alguma forma mitigada por fatores que decorrem das características do próprio setor, especificamente a prevalência, em termos históricos, de uma filiação com uma postura "militante". A quebra verificada terá sido motivada por diversos fatores, nomeadamente a questão económica (diminuição acentuada ou estagnação das remunerações, depreendendo-se que o pagamento da quota sindical teria um peso extraordinário sobre os rendimentos disponíveis) e a assunção de uma postura mais defensiva e reativa por parte dos sindicatos do setor, frustrando as expectativas dos afiliados. Este segundo ponto é colocado de forma explícita por um entrevistado:

alguma incapacidade que nós também tivemos de responder a coisas concretas. Porque a austeridade ofuscou de certa maneira a possibilidade de nós, digamos, provocarmos movimento no local de trabalho para exigir melhores condições. (...) o movimento que nós conseguimos gerar foi para não perder o que se tinha (...) E houve situações em que não conseguimos e isso naturalmente, em determinadas camadas de trabalhadores, gerou alguma frustração. (Entrevista a dirigente da Fiequimetal ${ }^{4}$, junho de 2018)

Mais recentemente, foi possível assinalar uma tendência de recuperação, mais percetível no caso de um sindicato específico - o Site-Sul -, muito embora a sua expressão seja moderada. As duas ordens de fatores que são colocados no centro da quebra de sindicalização motivaram a implementação de processos de reorganização, por exemplo, no seio das estruturas afetas à CGTP, ainda num período anterior à fase mais crítica da austeridade em virtude da aplicação do plano de 
ajustamento. Em termos gerais, as reorganizações, nomeadamente por via de processos de fusão, tiveram efeitos positivos no que respeita a perda de filiados exerceram um efeito de contenção - e permitiram potenciar os meios humanos e financeiros existentes. De igual modo, possibilitaram a partilha de experiências transversais aos vários subsetores do setor metalúrgico, o que se revelou enriquecedor em termos da capacidade de atuação dos dirigentes, que passaram a ser "transversais" a várias empresas de diferentes âmbitos, desenhando-se, assim, redes de interligação. Em alguns casos, medidas deste tipo terão ocasionado um crescimento exponencial em termos de filiação, para além de terem permitido aumentar a influência dos sindicatos. Outros efeitos apontados são os incentivos à participação dos trabalhadores e a promoção da solidariedade. O estabelecimento das redes de interligação, no caso de empresas de âmbito nacional, é uma forma de mitigar as insuficiências das estruturas, principalmente no que concerne a meios humanos disponíveis. Mas ainda que tenham sido feitos progressos, a inovação introduzida é considerada insuficiente.

A representatividade de género tende a constituir um problema no setor metalúrgico. Tratando-se de um setor em que prevalece uma força de trabalho do sexo masculino, o padrão de sindicalização reflete esse facto, verificando-se a mesma tendência no caso dos delegados sindicais. Tal suscita, desde logo, problemas em termos da representação sindical:

Apesar do conjunto destes setores que a Fiequimetal representa, que vão desde a metalurgia à química e indústrias elétricas, ser muito diverso e apesar de os homens serem a maioria, há setores onde existem muitas mulheres. (...) Ora, isto é um problema sério que temos. Não tem depois uma relação direta com a presença das mulheres nos órgãos de direção e de decisão. (Entrevista a dirigente da Fiequimetal, junho de 2018)

Têm vindo a ser feitos esforços no sentido de contrariar essa tendência, como, por exemplo, a criação de um grupo de trabalho para a igualdade de género. Porém, ainda que o número de mulheres a exercerem funções de delegado sindical possa estar a crescer, é insuficiente face ao número de associadas. A ocupação de cargos de direçãoé ainda mais reduzida. A sobre representação do sexo masculino é, portanto, uma limitação que tem sido difícil de ultrapassar, desde logo por questões culturais e outras ligadas à vida familiar. Em termos etários, continua a predominar uma faixa "madura" que se aproxima, de acordo com um dirigente sindical entrevistado, dos 50 anos. Essa média de idades repercute-se nas estruturas sindicais que compõem a Fiequimetal, corroborando as perceções que apontam para um sindicalismo "envelhecido".

Nos outros dois setores, das telecomunicações e dos transportes, a tendência de quebra de sindicalização seguida de uma inflexão também se verifica, ainda que 
com várias nuances. Por exemplo, segundo fonte sindical, no caso específico de um sindicato do setor das telecomunicações, o Sinttav ${ }^{5}$, verificaram-se perdas sensivelmente até 2007, as quais são maioritariamente atribuídas aos efeitos decorrentes dos processos de flexibilização do emprego. No entanto, a concretização da venda da PT à Altice (em 2018) funcionou como elemento desencadeador de novos processos e, em particular, potenciou a captação de novos sócios, verificando-se, portanto, segundo a mesma fonte, uma inflexão das taxas de sindicalização. Outra razão que nos foi apontada prende-se com a expansão das empresas de trabalho temporário, muito presentes no setor das telecomunicações, nomeadamente ao nível dos call centres. Aliás, no caso de um dos sindicatos estudados, estas empresas tornaram-se numa das áreas de intervenção prioritárias.

No setor dos transportes - que teve a TAP como empresa de referência - as fontes sindicais também fazem referência a uma tendência de crescimento do número de filiados. No caso específico de um dos sindicatos abrangidos pelo nosso estudo, oSNPVAC ${ }^{6}$, o crescimento do número de sócios foi significativo e deveu-se em muito ao processo de privatização da TAP e às novas condições oferecidas aos seus trabalhadores. Nesse setor, e no que se refere especificamente aos tripulantes de cabine, a representatividade em termos de género e de idades é equilibrada. Convém a esse propósito lembrar que este sindicato representa um grupo muito específico, cujas características profissionais restringem o acesso à profissão a camadas mais jovens e onde a questão do género também se esbate.

A questão da representatividade, concretamente na sua vertente numérica, não deixa, portanto, de se articular intimamente com outros dois critérios. Por um lado, com o critério público/ privado, tendo ficado bem patente a influência exercida pelos processos de privatização, e pela degradação das condições de trabalho e flexibilização contratual que lhes está associada nos casos da PT/Altice e da TAP, sobre os índices de sindicalização. Em ambos os casos, é de assinalar a existência de uma tendência de recuperação. Por outro, com o critério inovação, em particular no que concerne os métodos de captação de novos membros, reorganização sindi-

cal e comunicação com os associados e o exterior. Sobre este critério, vejamos o que foi apurado em relação aos três setores em análise.

\section{Inovação}

Muito embora desde sempre elencada como uma prioridade de qualquer sindicato, a captação de novos membros, nomeadamente entre as franjas mais precarizadas e por isso mais afastadas dos sindicatos, nem sempre foi alvo de estratégias específicas. Por exemplo, no caso do setor metalúrgico, não foram mencionadas novas estratégias orientadas para esse objetivo: “Não... nestas coisas não há muito 
que inventar (...) os trabalhadores estão lá, estão no local de trabalho, na empresa. Onde nós temos estrutura tratamos os trabalhadores com vínculo precário de igual modo. Contactamos todos, não fazemos diferenciação." (Entrevista a dirigente da Fiequimetal, junho de 2018)

A inovação no sentido da integração das novas tecnologias na atividade dos sindicatos, tanto em termos da comunicação interna como com o exterior, não é uma questão consensual, sendo de referir a existência de perspetivas bastante diferenciadas. No caso do setor metalúrgico, as novas tecnologias e plataformas de comunicação como o Facebook, site e mailing list têm um estatuto "ambíguo" relativamente ao papel que podem desempenhar em questões como o contacto com os membros e a forma de comunicação em geral, ou mesmo como ferramenta importante para a captação de novos filiados:

Acho que é uma forma importante de captação de novos membros, na medida em que permite uma maior divulgação dos sindicatos, das suas posições. Mas as organizações sindicais têm uma particularidade relativamente a outros tipos de organizações: o seu principal veículo de comunicação é a presença junto das pessoas, é o contacto. O resto é tudo complementar. (Entrevista a dirigente da Fiequimetal, junho de 2018)

Não obstante as reservas manifestadas em relação ao "virtuosismo" do e-sindicalismo, o site foi referido como um veículo muito importante de transmissão de informação e, por isso, alvo de uma atualização quase constante.

No caso do setor das telecomunicações, a inovação por meio da introdução de novas tecnologias no quotidiano sindical parece estar a ganhar ímpeto, apesar de ser claro que estas não podem substituir, em absoluto, métodos mais tradicionais.

Nós apostamos nas novas tecnologias como forma de comunicar com os membros e com o exterior, só que não eliminamos a informação tradicional. Por exemplo, nós temos uma página (...) há uma reunião, a gente faz um resumo e põe lá. Por exemplo, estive agora em Madrid e está lá uma informação sobre o que se passou. Depois vai o relatório para os dirigentes. Apostamos nas vertentes todas, mas aquilo que é tradicional - ter um comunicado no placard, dar um comunicado em mão aos trabalhadores - não se pode substituir. (Entrevista a dirigente do Sinttav, março de 2018)

As novas tecnologias também começam a ocupar um lugar nos métodos de captação de novos membros, mas de forma residual. Por exemplo, ainda que a ficha de inscrição seja disponibilizada online no caso do sindicato mencionado, foram poucas as sindicalizações por essa via. A importância do contacto pessoal, direto, é enfatizada de forma clara, continuando a ser considerado o meio mais eficaz no que diz respeito à filiação e sua manutenção. Por outro lado, a escassez de meios humanos para levar a cabo a 
gestão de conteúdos em plataformas como o Facebook é apontada como um problema, determinando que esta rede social não seja tão utilizada, para além de suscitar reservas quanto à transparência das participações e veracidade dos conteúdos por vezes avançados pelos utilizadores. Já a utilização do site para a divulgação de informação como comunicados e resoluções parece ser mais consensual.

O panorama revelou-se totalmente diferente no setor dos transportes. Para o sindicato que representa os tripulantes de cabine, a utilização das redes sociais no quotidiano da vida interna do sindicato - ou seja, na sua relação com os membros - é de extrema importância, principalmente tendo em conta a natureza das funções exercidas. O seguinte exemplo a propósito da utilização do Facebook é bastante elucidativo a esse respeito:

Sou tripulante e acontece um problema: se posso ou não fazer o voo, por exemplo.
Entrei em circadiano, já não podia fazer. Coloco a minha questão no grupo que nós te-
mos de questões e dúvidas e posso dizer-lhe que $99 \%$ das questões são respondidas
passados 5 minutos. E é um grupo aplaudido por todas as pessoas. A direção é que
responde, como direção. E as pessoas estão muito satisfeitas porque nunca tinham a
resposta quase automática à questão colocada. E estamos a falar que todos os dias há 4
ou 5 questões a serem respondidas a qualquer hora, por dia. Portanto, é 24 sobre 24
horas. (Entrevista a dirigente do SNPVAC, janeiro de 2018)

Curiosamente, e apesar de ser clara a aposta nas novas tecnologias e na inovação, no caso deste sindicato em particular, não lhes é atribuído um papel relevante no que diz respeito à captação de novos sócios. Esta é feita "internamente", através do contacto direto entre colegas de profissão no seu dia-a-dia. Acresce que, como referiu um entrevistado, "qualquer pessoa que entra na companhia já sabe que deve sindicalizar-se... porque o nosso sindicato é forte (...) as pessoas não querem não estar sindicalizadas".

A inovação também ocorreu no plano das estratégias utilizadas e do estabelecimento de alianças com outros atores da sociedade civil. As alianças encerram um enorme potencial de legitimação das campanhas sindicais e de enquadramento da mensagem que se pretende passar para "fora". Um exemplo importante de inovação com base na conceção de campanhas que envolvem diretamente a sociedade civil, e que amplificam o poder societal, foi levado a cabo pelo sindicato dos tripulantes de cabine (SNPVAC) em relação ao processo de privatização da TAP (portanto, para além do critério inovação, neste exemplo está também em jogo o critério público/privado). Tratou-se da campanha "Não TAP os olhos" contra a privatização da empresa. Criada por ativistas sindicais e por uma figura pública de relevo, o cineasta António Pedro Vasconcelos, o "Não TAP os olhos" - "o braço armado da luta contra a privatização" - foi uma inovação porque: 
Saiu para fora da esfera dos sindicatos. As pessoas ouvem melhor se for alguém da sociedade civil a explicar as coisas do que um sindicalista. Se o Arménio Carlos for à televisão, metade da população já olha de lado (...). O português ainda é muito conservador, preconceituoso, por mais que digamos que não. E esse preconceito atinge os sindicatos também. (Entrevista a dirigente doSNPVAC, janeiro de 2018)

A criação de movimentos deste tipo, através de alianças com a sociedade civil, é perspetivada como uma forma de maximizar a transmissão da mensagem sindical, "de abrir os olhos às pessoas, de ter tempo de antena... poder ficar lá o bichinho e as pessoas pensarem duas vezes", como foi mencionado pelo mesmo entrevistado. No caso concreto desta campanha, o impacto na esfera pública foi considerável e obrigou ao posicionamento explícito de atores políticos e da sociedade civil, colocando na ordem do dia a discussão sobre o estatuto da TAP como empresa de interesse público e as consequências da privatização.

Outro exemplo de inovação é fornecido pelas estruturas de representação coletiva dos trabalhadores da PT/Altice (composta pela CT MEO7, Sinttav, STPT8, Sindetelco ${ }^{9}$, SNTCT10 ${ }^{10}$, STT11, FE ${ }^{12}$, Sitese ${ }^{13}$ e Sinquadros ${ }^{14}$ ) que se aliaram no âmbito da convocação da greve de 21 de julho de 2017. Tratou-se, sem dúvida, de um grande desafio tendo em conta as especificidades dos seus pontos de vista em matéria de objetivos e estratégias. O que importa, por isso, sublinhar é a capacidade de enquadrar diferentes posicionamentos à luz de um problema comum às várias estruturas. Retomando a sistematização levada a cabo na secção 2, é possível identificar uma utilização bem-sucedida de competências estratégicas como a intermediação e o framing (Lévesque e Murray, 2010), permitindo a mobilização do poder societal, tanto na vertente colaborativa ${ }^{5}$ (estabelecimento de uma aliança com vista à convocação da greve) como na discursiva (enquadramento das circunstâncias e objetivos da greve de forma a legitimá-la perante a sociedade civil e a recolher apoios). O seguinte fragmento de entrevista é ilustrativo a esse propósito:

As estruturas todas, com pontos de vista diferentes, com posicionamentos diferentes, conseguiram perceber que o fundamental é a luta conjugada. Até hoje, continuam todos. Está a CT, estão os sindicatos, todos na luta. Pela primeira vez, nem no tempo do Todo Bom, em 1994, que foi quando nós travámos a maior luta de sempre na PT, nem nesse tempo nós conseguimos ter as estruturas todas com o mesmo projeto. (...) É um trabalho de todos, uma responsabilização e um trabalho de todos. Deixando que cada um expressasse os seus pontos de vista, tivesse as suas opiniões, sem se forçar nada, mas todos perceberam o que estava aqui em causa. (Entrevista a dirigente doSinttav, março de 2018)

A mobilização do poder societal é também particularmente evidente na decisão das estruturas de representação coletiva dos trabalhadores da PT/Altice de levarem a 
cabo pelo menos uma ação pública por mês durante o ano de 2018. O objetivo era não deixar a questão da transmissão de estabelecimento esmorecer, mantendo assim a opinião pública mobilizada, o que, em princípio, trabalharia a favor das pretensões dos sindicatos. As tribunas públicas ${ }^{16}$ organizadas no Porto e em Lisboa são exemplos de ações desenvolvidas nesse âmbito. Ao serem acompanhadas pela comunicação social, conferiram grande visibilidade à questão. Para além de assinalarem as datas de transmissão de estabelecimento de trabalhadores da PT / Altice, carregando por isso um enorme simbolismo, essas ações também envolveram a mobilização do poder associativo, potenciando-o, pois, como reconhecem Lehndorff, Dribbush e Schulten (2017), aquele depende em grande medida das atividades desenvolvidas no e pelo sindicato.

\section{Conflito/Negociação}

A análise centrada no binómio conflito/negociação revelou resultados interessantes para os três setores. Observou-se uma aposta clara dos sindicatos em uma estratégia de pendor conflitual em detrimento de uma outra mais centrada na negociação, principalmente entre os sindicatos afetos à CGTP. A preponderância do conflito foi potenciada pelos constrangimentos impostos pela aplicação das medidas de austeridade, que levaram, entre outras coisas, à introdução de alterações profundas na legislação laboral, cerceando a capacidade de atuação dos sindicatos. Tal como aconteceu um pouco por toda a Europa, o sistema de negociação coletiva foi colocado sob pressão, não se tendo ainda verificado a completa reversão dessa tendência, nomeadamente da diminuição acentuada da cobertura das convenções negociadas, apesar de ser assinalável alguma recuperação (ILO, 2018; Müller, Vandaele e Waddington, 2019; Távora e González, 2016). Por outro lado, as alterações à legislação laboral, em particular as relativas ao tempo de trabalho e à retribuição pelo trabalho extraordinário mencionadas anteriormente, repercutiram-se no plano conflitual, acentuando-o. Tal não deixa de ser visível ao nível dos estudos de caso contemplados.

Tanto no setor das telecomunicações como no dos transportes, a opção pela greve como estratégia para obter concessões ou travar processos altamente nocivos para os trabalhadores ilustra a preponderância da vertente conflitual. No caso das telecomunicações, referimo-nos concretamente à greve de 21 de julho de 2017, levada a cabo pelos trabalhadores da PT na sequência da polémica das transmissões de estabelecimento, e que conduziu a um recuo da empresa em relação a futuras transmissões e a uma alteração legislativa ${ }^{17}$ com vista ao reforço dos direitos dos trabalhadores. Essa alteração legislativa corrobora a apreciação de Lehndorff, Dribbush e Schulten (2017) de que os sindicatos são capazes de refrear a fragmentação da negociação coletiva em alguns casos e "forçar" alterações legislativas 
favoráveis, nomeadamente através do reforço de alianças que transcendem a esfera política tradicional. Neste caso em particular, por meio da mobilização do poder societal na sua vertente discursiva. A tensão no seio da empresa foi crescendo desde a sua compra pela Altice em 2015, contribuindo para o exacerbamento do conflito motivado pelas alterações complexas no seio da empresa. Neste caso concreto, os processos de privatização parecem estar intimamente relacionados com a preponderância de uma dimensão conflitual.

O estudo de caso centrado na TAP é também ele emblemático a esse respeito. A eleição da greve como forma de luta por parte dos sindicatos veio responder à indisponibilidade da administração da TAP para negociar. Como era referido por um dirigente sindical, os processos negociais encontravam-se completamente bloqueados:

Neste momento [o processo negocial] está bloqueado. Eles querem negociar, querem negociar a favor deles, só. Neste momento, eles assumiram três compromissos, acordados, escritos, e há meses que não os estão a cumprir. E além disso denunciaram o acordo de empresa. (Entrevista a um dirigente sindical, janeiro de 2018)

O setor metalúrgico ecoa esta tendência de maior expressão da dimensão conflitual. O estudo de caso da Autoeuropa exprime muito bem a maior preponderância do conflito. Se é certo que durante os anos de austeridade, ou nos que a antecederam, a empresa foi posta à prova a vários níveis (por exemplo, a crise no setor automóvel no início dos anos 2000 exigiu que fossem colocadas em prática soluções como o acordo dos down days ou o envio de trabalhadores para outras fábricas europeias), procurando gerir as crises em clima de diálogo, em 2017 a simples produção de um novo veículo, associada a um processo de substituição de um líder histórico da comissão de trabalhadores, ditou um processo de conflitualidade pouco comum na cultura da empresa.

Na sua origem esteve o diferendo relativo à introdução do novo horário que previa a obrigatoriedade do trabalho ao sábado e um terceiro turno de forma a cumprir as metas de produção de um novo modelo: o veículo T-Roc. O conflito desenrolou-se em torno da atuação de três atores: administração, sindicatos e comissão de trabalhadores (o interlocutor preferencial da administração), e teve a particularidade de colocar em confronto direto sindicatos e comissão de trabalhadores. Do ponto de vista dos primeiros, o conflito até terá tido até algumas vantagens:

Uma delas foi os trabalhadores terem descoberto - não é que não soubessem - que existem estruturas sindicais que vão para além da comissão de trabalhadores e que também se podem socorrer delas. Essa é uma vantagem. A outra foi que o sindicato, 
contrariamente ao que acontecia até aquela altura, passou a ser ouvido pela administração. (Entrevista a dirigente da Fiequimetal, junho de 2018)

Por outro lado, o campo sindical, mais concretamente o sindicato Site-Sul (afeto à CGTP) terá desempenhado um papel determinante na convocação da primeira greve na Autoeuropa desde que a fábrica começou a laborar em 1995:

[A greve] Foi convocada pelo nosso sindicato [Site-Sul]. Aquilo foi assim: eles tinham decidido a greve e, entretanto, para discutir o pré-aviso de greve com os trabalhadores o sindicato marcou um plenário. (...) O sindicato fez o plenário no dia 28 porque a CT estava demissionária e não havia outra forma para os trabalhadores reunirem que não fosse o sindicato marcar o plenário. (Entrevista a dirigente da Fiequimetal, junho de 2018)

A greve de 30 de agosto de 2017 teve repercussões na esfera pública e mediática, lançando o espectro da deslocalização, da qual os sindicatos seriam considerados culpados por terem optado por essa via. A realidade é que, em termos práticos, e apesar de ter colocado o conflito sobre os horários sob enorme escrutínio, a greve "apenas" levou a administração a relançar as negociações e a receber os sindicatos. As reivindicações em jogo não foram de facto atendidas. Nunca é demais recordar que, no caso específico da Autoeuropa, os processos negociais têm por norma a comissão de trabalhadores como interlocutor preferencial da administração. Acresce ainda que este conflito constituiu um exemplo bastante expressivo de uma mobilização do poder societal malsucedida. O mal-estar no interior da fábrica, a disputa entre a comissão de trabalhadores e o sindicato Site-Sul, e o braço de ferro com administração tiveram uma enorme projeção mediática, com vários debates televisivos, fomentando uma discussão acesa no espaço público. A opinião pública dividiu-se em relação à legitimidade das posições dos trabalhadores, bem como da comissão de trabalhadores por um lado e do Site-Sul por outro. Não raras vezes, os trabalhadores da Autoeuropa foram caracterizados como "privilegiados" num contexto em que a grande maioria ainda sofria os efeitos decorrentes da crise. Ficou bem patente que o Site-Sul em particular teve grande dificuldade em mobilizar o seu poder societal na vertente discursiva. Demonstrou incapacidade em fornecer um padrão de interpretação da crise na Autoeuropa e de, assim, influenciar a opinião pública a seu favor, por forma a legitimar as reivindicações colocadas.

\section{Nacional/Internacional}

O binómio nacional/internacional é um critério analítico que nos permite retirar ilações quanto ao equilíbrio entre desafios internos e externos dos sindicatos. Desde 
logo é possível fazer referência a um traço comum a todos os sindicatos: o estabelecimento da esfera nacional como prioritária. Principalmente na esteira das medidas de austeridade e das suas consequências, as preocupações fundamentais foram basicamente de cariz nacional, gravitando em torno de questões como os salários (exigências de aumentos salariais), precariedade e negociação coletiva (particularmente, preocupações com a erosão do direito à negociação coletiva, com a sua descentralização e consequente desmantelamento, e com a caducidade das convenções coletivas de trabalho). Em boa verdade, estas não são questões estritamente portuguesas - em vários países, os sindicatos confrontam-se com problemas similares - mas jogam-se no plano dos enquadramentos legais nacionais, daí serem aqui identificadas com a vertente nacional. Não obstante esse facto, a dimensão internacional não deixa de estar presente e de ser vista como importante, muito embora seja claramente secundária. Todos os sindicatos abrangidos por este estudo são filiados numa organização sindical internacional e todos reportaram retirarem vantagens dessa filiação, mencionando, em particular, as decorrentes do contacto em rede. No caso específico das estruturas sindicais do setor metalúrgico, é esse aspeto que é enfatizado mais do que a ação sindical internacional propriamente dita, pois, como foi assinalado, as federações internacionais por vezes "Não desempenham esse papel como deviam e quando o fazem a nível de empresa são muito arrastados, ou levados se quiser, para as grandes empresas. Até há uma linha de atuação no sentido de puxar para trás." (Entrevista a dirigente da Fiequimetal, junho de 2018)

De forma similar, os sindicatos do setor das telecomunicações que foram auscultados também possuem filiação internacional, na UNI ${ }^{18}$. Essa estrutura é mencionada como um elemento importante no que concerne a resolução de conflitos com foco em empresas multinacionais. Tem facilitado a construção de ações de âmbito transnacional, como, por exemplo, as levadas a cabo contra a Altice/Portugal (designação adotada desde 2018). Curiosamente, não existem indícios da intervenção da UNI em questões como as transmissões de estabelecimento levadas a cabo por aquela empresa. A estratégia seguida pelos sindicatos situou-se na esfera nacional e, como vimos, num plano conflitual que se alicerçou numa estratégia de mobilização e de recurso à greve.

Os sindicatos do setor dos transportes exibem um padrão bastante diferente num dos casos. $\mathrm{O}$ sindicato que representa os tripulantes de cabine assume como uma das suas bandeiras, a par das preocupações decorrentes do recente processo de venda da TAP, a ação que tem como foco a transportadora aérea low cost Ryanair. Essa ação desenrola-se no plano internacional e é estruturada a partir das ligações com sindicatos de outros países europeus, nomeadamente da Alemanha, Bélgica, Espanha, Holanda e Itália ${ }^{19}$. No entanto, muito 
embora os sindicatos envolvidos façam parte, na sua maioria, da mesma organização internacional de tripulantes de cabine (a EurECCA ${ }^{20}$ ), a ação contra a Ryanair não foi articulada através dela. Tomados em conjunto, quanto a este critério analítico, os nossos estudos de caso sugerem que a grande vantagem retirada da filiação internacional é o contacto em rede e que as questões nacionais continuam a ter a prioridade no estabelecimento das agendas sindicais.

\section{Notas finais}

Os anos de austeridade colocaram o sindicalismo numa posição particularmente difícil e, como tal, a suscitar um olhar sobre o poder sindical como algo em crescente contração. Mas a nossa investigação permitiu concluir que a evolução recente dos recursos de poder aconteceu, ela própria, de forma assimétrica, tanto no que se refere à relação dos vários tipos de poder entre si, como na forma como os vários recursos de poder evoluíram consoante o setor de atividade. Aliás, tal não deixa de ser congruente com as trajetórias de um conjunto mais alargado de países no plano Europeu, como é evidenciado por Lehndorff, Dribbush e Schulten (2017). Ainda que estes autores sublinhem o quadro de crescente divergência dos percursos dos sindicatos europeus nos últimos anos, os seus estudos de caso nacionais ressaltam, tal como o nosso campo empírico, o comportamento não só dinâmico como complexo dos recursos de poder. Dito de outra forma, os desafios colocados aos vários países são similares, mas a capacidade de lidar com os mesmos difere substancialmente.

No caso português, o contexto de austeridade funcionou como um estímulo que alterou a preponderância dos recursos de poder para a ação sindical, assistindo-se ao robustecimento de determinadas formas de poder, enquanto outras foram relegadas para uma posição que lhes confere uma influência mais marginal. Por um lado, duas formas de poder - o poder estrutural e o poder institucional - evidenciaram sinais de maior fraqueza de forma generalizada. As medidas impulsionadas pela aplicação do Memorando da Troika trouxeram a austeridade e com ela as medidas de ajustamento fiscal e estrutural e consequentes restrições orçamentais, o aumento do desemprego e as alterações à legislação laboral no sentido de uma maior flexibilização indutora de precariedade, o que teve impactos negativos sobre essas duas formas de poder. Por um lado, não deixa de ser verdade que o desemprego recuou consideravelmente entre 2015 e 2019, o que poderia contribuir para uma recuperação do poder estrutural dos sindicatos. Ainda assim, a suceder tal recuperação, a mesma seria tímida e não necessariamente direta. Por outro, no plano do poder institucional, poucas mudanças se têm verificado, uma vez que as alterações de 2012 à legislação laboral ainda não foram 
totalmente revertidas, nomeadamente no que diz respeito à caducidade da contratação coletiva, entre várias outras matérias.

Situações como a referida continuam a exercer um efeito pernicioso sobre o poder sindical. Para além de restringirem a possibilidade de os sindicatos compensarem, através da mobilização do poder institucional, as perdas nos planos estrutural e organizacional (Lehndorff, Dribbush e Schulten, 2017). Neste ponto, os critérios conflito/negociação e público/privado proporcionaram informações valiosas ao enfatizarem as dificuldades colocadas aos sindicatos dos diferentes setores. Em particular, é importante sublinhar nos três setores o recurso generalizado a estratégias de conflito, nomeadamente à greve, em detrimento do enfoque na negociação. Tal facto estará certamente relacionado com a perda de poder estrutural assinalada, a qual pode contribuir para enfraquecer a posição negocial dos sindicatos. Ou seja, como referimos no início, se as assimetrias de poder na estrutura da sociedade capitalista são vincadas e as instâncias de diálogo ficam bloqueadas, o conflito (greve) - ainda que legitimamente percecionado como a "outra face" da negociação - acaba por ser incorporado como um recurso de que qualquer sindicato se pode socorrer de modo mais frequente, mesmo que tal se afigure mais recorrente entre as estruturas sindicais próximas da CGTP. O enfraquecimento dos poderes estrutural e institucional - no caso deste último, também bastante evidente em países como a Grécia e Espanha - foi compensado nos planos associativo e societal. Essas duas formas de poder evidenciaram sinais de revigoramento. Contrariamente ao veiculado pelo senso comum, os sindicados visados pelos nossos estudos de caso vêm evidenciando alguma recuperação em termos de filiação (sobretudo entre o segmento mais precário dos trabalhadores, que, entretanto, conquistou vínculos mais estáveis). Principalmente no plano dos sindicatos dos setores das telecomunicações e dos transportes, esse aumento está muito relacionado com os processos de privatização das empresas contempladas.

As novas estratégias empresariais nos casos da PT/Altice e da TAP impuseram condições extremamente difíceis aos trabalhadores, levando-os a procurar os sindicatos. No que concerne à Autoeuropa (setor metalúrgico), o conflito em torno dos horários e da laboração contínua também terá estimulado um aumento da filiação. Em todo o caso, embora nos tenha sido reportado nesses termos, esse aumento carece de "vigilância" apertada em futuros trabalhos, desde logo porque contrasta com o período anterior de perdas significativas. Ainda assim, tomando-o como fidedigno, esse aumento de filiação permite estabelecer uma correlação positiva entre processos de privatização e alguma recuperação do poder organizacional/associativo, o que significa também uma ligação dinâmica entre os critérios "público/privado" e "representatividade" e o poder organizativo/associativo. 
Ainda que possa parecer contraditório, o poder societal - sobretudo na esteira dos contributos de Schmalz e Dörre (2013) e Lehndorff, Dribbush e Schulten (2017) - terá sido o recurso de poder dos sindicatos que ganhou maior fôlego com a austeridade e no período subsequente, sobretudo na sua vertente discursiva, o que se refletiu na capacidade de os sindicatos comunicarem. Não obstante o clima de crise económica e de contenção orçamental, foi possível, ainda que com alguma dificuldade por vezes, aos sindicatos avançarem com as suas reivindicações e tornarem-nas legítimas aos olhos da opinião pública, conseguindo dessa forma o apoio da sociedade. Tanto no caso da PT-Altice como no da TAP, os sindicatos conseguiram enquadrar de forma bastante efetiva as suas reivindicações e mensagens.

O caso da transmissão de estabelecimento na PT-Altice, por exemplo, reuniu um apoio amplo e teve um impacto bastante negativo sobre a imagem pública da empresa, favorecendo sobremaneira as reivindicações sindicais. O mesmo se mostrou válido para o setor dos transportes. Como antes se sugeriu, a campanha "Não TAP os olhos" deu testemunho cabal da mobilização do poder societal dos sindicatos, tanto no plano da cooperação como no discursivo. Porém, no cômputo geral, pode ser dito que a vertente discursiva do poder societal foi a que conheceu mais desenvolvimentos. As alianças com os movimentos sociais, que corresponderiam a avanços na vertente colaborativa deste recurso de poder, não se têm materializado, ficando circunscritas ao domínio da retórica sindical.

Por último, importa referir que a nossa investigação convergiu num outro ponto com a análise de Lehndorff, Dribbush e Schulten (2017): a relação entre os recursos de poder institucional e de poder societal (mormente no que concerne o papel dos sindicatos como atores políticos autónomos, capazes de estabelecer alianças com uma multiplicidade de atores sociais e de influenciar o discurso público) é um dos desafios mais proeminentes que se colocam aos sindicatos, nomeadamente aos que foram visados neste estudo.

\section{Notas}

Por decisão pessoal, os/as autores do texto escreveram segundo as regras do novo acordo ortográfico.

1 Este trabalho teve o apoio financeiro da Fundação para a Ciência e Tecnologia (FCT/MEC) através de fundos nacionais e foi cofinanciado pelo FEDER através do Programa Operacional Competitividade e Inovação COMPETE 2020 no âmbito do projeto PTDC/IVC-SOC/3533/2014 - POCI-01-0145-FEDER-016808.

2 De acordo com Behrens, Hamann e Hurd (2004), a revitalização sindical pode ocorrer em quatro dimensões: a) dimensão da filiação; b) dimensão económica; c) dimensão 
política; e d) dimensão institucional, que abrange a estrutura interna dos sindicatos, a dinâmica e a identidade.

No contexto da Autoeuropa foram realizadas entrevistas a responsáveis sindicais da Federação Intersindical das Indústrias Metalúrgicas, Químicas, Elétricas, Farmacêutica, Celulose, Papel, Gráfica, Imprensa, Energia e Minas (Fiequimetal) e do Sindicato dos Trabalhadores das Indústrias Transformadoras, Energia e Ambiente do Sul (Site-Sul), bem como da comissão de trabalhadores. No quadro da TAP, foram entrevistados responsáveis sindicais e membros do Sindicato Nacional do Pessoal de Voo da Aviação Civil (SNPVAC), do Sindicato dos Trabalhadores da Aviação e Aeroportos (Sitava) e do Sindicato dos Técnicos de Manutenção e Aeronaves (Sitema), bem como da comissão de trabalhadores. Por fim, na PT/Altice foram entrevistados responsáveis sindicais e membros do Sindicato Nacional dos Trabalhadores das Telecomunicações e Audiovisual (Sinttav), do Sindicato dos Trabalhadores do Grupo Portugal Telecom (STPT), do Sindicato Nacional dos Trabalhadores de Correios e Telecomunicações (SNTCT) e do Sindicato Democrático dos Trabalhadores das Comunicações e dos Media (Sindetelco), bem como da comissão de trabalhadores da MEO.

Federação Intersindical das Indústrias Metalúrgicas, Químicas, Elétricas, Farmacêutica, Celulose, Papel, Gráfica, Imprensa, Energia e Minas - CGTP-IN.

5 Sindicato Nacional dos Trabalhadores das Telecomunicações e Audiovisual.

6 Sindicato Nacional do Pessoal de Voo da Aviação Civil.

7 Comissão de Trabalhadores da MEO.

8 Sindicato dos Trabalhadores do Grupo Portugal Telecom.

9 Sindicato Democrático dos Trabalhadores das Comunicações e dos Media.

10 Sindicato Nacional dos Trabalhadores de Correios e Telecomunicações.

11 Sindicato dos Trabalhadores de Telecomunicações e Comunicação Audiovisual.

12 Federação dos Engenheiros.

13 Sindicato dos Trabalhadores e Técnicos de Serviços, Comércio, Restauração e Turismo.

14 Sindicato de Quadros das Comunicações.

15 Ainda que, conforme a perspetiva aqui explorada, o poder societal na sua vertente colaborativa contemple a capacidade de os sindicatos construírem coligações, principalmente com outros atores sociais que não os sindicatos, considera-se que o estabelecimento da aliança no âmbito da convocação da greve de 21 de julho de 2017 também pode ser tomado como um exemplo dessa mesma vertente colaborativa.

16 As tribunas públicas consistiram na realização de reuniões em locais públicos, abertas à participação de qualquer cidadão, em que a questão da "transmissão de estabelecimento" (mudança compulsiva para outra empresa do grupo) esteve no centro da discussão. O principal objetivo era o esclarecimento das questões subjacentes àquela situação e colocar o problema no espaço público.

17 Tratou-se da Lei $\mathrm{n}^{\mathrm{o}} 14 / 2018$.

18 A UNI Sindicato Global, com base em Nyon, Suíça, representa mais de 20 milhões de trabalhadores de cerca de 150 países, nos setores do trabalho qualificado e dos serviços - os setores com maior crescimento em termos mundiais. 
19 Conjuntamente com Portugal, estes foram os países envolvidos na greve de 28 de setembro de 2018.

20 A Associação Europeia de Tripulantes de Cabine, EurECCA, é integrada por dez sindicatos de tripulantes de cabine dos seguintes países: França, Espanha, Holanda, Alemanha, Itália, Portugal, Suíça, Irlanda e Grécia.

\section{Referências}

Behrens, M., Hamann, K., e Hurd, R. (2004). Conceptualizing labour union revitalization. Em C. Frege, e J. Kelly (Eds.), Varieties of unionism: Strategies for union revitalization in a globalizing economy (pp. 11-29). Nova Iorque: Oxford University Press.

Campos Lima, M. P. (2017). A grande regressão da negociação coletiva: Os desafios e as alternativas. Em M. Carvalho da Silva, P. Hespanha e J. Castro Caldas (Coords.), Trabalho e políticas de emprego: Um retrocesso evitável (pp. 245-299). Coimbra: Conjuntura Actual Editora.

Campos Lima, M. P., e Martin Artiles, A. (2011). Crisis and trade union challenges in Portugal and Spain: Between general strikes and social pacts. Transfer, 17(3), 387-402.

Costa, H. A. (2018). O sindicalismo ainda conta? Poderes sindicais em debate no contexto europeu. Lua Nova, 104, 259-285. DOI: 10.1590/0102-259285/104

Crouch, C. (2017). Membership density and trade union power. Transfer - European Review of Labour and Research, 23(1), 47-61. DOI: 10.1177/1024258916673533

Dörre, K. (2017). Trade unions, power resources and public sociology: A self-experiment. Österreichische Zeitschrift für Soziologie, 42(2), 105-128.

Estanque, E., Costa, H. A., e Silva, M. C. (2015). O futuro do sindicalismo na representação sociopolítica. Em A. Freire (Org.), O futuro da representação política democrática (pp. 119-142). Lisboa: Nova Vega.

Gumbrell-McCormick, R., e Hyman, R. (2013). Trade unions in Western Europe: Hard times, hard choices. Oxford: Oxford University Press.

Hyman, R. (2001). Understanding European trade unionism: Between market, class and society. Londres: Sage.

ILO. (2018). Decent work in Portugal 2008-18. From crisis to recovery. Genebra: International Labour Office. Disponível em

https://www.ilo.org/global/publications/books/WCMS_646867/lang - en/index.htm

Jensen, C. S., Madsen, J. S., e Due, J. (1995). A role for pan-European trade union movement? Possibilities in European IR-regulations. Industrial Relations Journal, 26(1), 4-18. DOI: 10.1111/j.1468-2338.1995.tb00719.x

Koukiadaki, A., Távora I., e Martínez Lucio, M. (2016). Joint regulation and labour market policy in Europe during the crisis: A seven-country comparison. Em A. Koukiadaki., I. Távora, M. Martínez, e Lucio M. (Eds.), Joint regulation and labour market policy in Europe during the crisis (pp. 7-134). Bruxelas: European Trade Union Institute.

Larson, S., e Nissen, B. (Eds.) (1987). Theories of the labor movement. Detroit: Wayne State University Press. 
Lehndorff, S., Dribbush, H., e Schulten, T. (2017). European trade unions in a time of crises: An overview. Em S. Lehndorf, H. Dribbush, e T. Schulten (Eds.), Rough waters: European trade unions in a time of crises (pp. 7-34). Bruxelas: European Trade Union Institute.

Lévesque, C., e Murray, G. (2010). Understanding union power: Resources and capabilities for renewing union capacity. Transfer, 16(3) 333-350. DOI: $10.1177 / 1024258910373867$

McGuire, D. (2014). Analysing union power, opportunity and strategic capability: Global and local union struggles against the General Agreement on Trade in Services (GATS). Global Labour Journal, 5(1), 45-67. DOI: 10.15173/glj.v5i1.1147

Müller, T., Vandaele, K., e Waddington, J. (Eds.) (2019). Collective bargaining in Europe: Towards an endgame (Vol. I). Bruxelas: European Trade Union Institute (ETUI).

Paquet, R., Tremblay, J.-F., e Gosselin, E. (2004). Des théories du syndicalisme: Synthèse analytique et considérations contemporaines. Relations Industrielles/Industrial Relations, 59(2), 295-320. DOI: 10.7202/009543ar

Schmalz, S., e Dörre, K. (2013). El planteamiento de los recursos del poder. Cidade do México: Fundación Friedrich Ebert. Disponível em https:// bit.ly/2v3GMiE

Schmalz, S., e Thiel, M. (2017). IG Metall's comeback: Trade union renewal in times of crisis. Journal of Industrial Relations, 59(4), 465-486. DOI: 10.1177/0022185617714818

Silva, M. C. da, Hespanha, P., e Caldas, J. C. (Orgs.) (2017). Trabalho e políticas de emprego: Um retrocesso evitável. Lisboa: Actual Editora.

Silver, B. (2003). Forces of labor: Workers' movements and globalization since 1870. Cambridge: Cambridge University Press.

Távora, I., e González, P. (2016). The reform of joint regulation and labour market policy during the current crisis: National report on Portugal. Em A. Koukiadaki, I. Távora, e M. Martínez (Eds.), Joint regulation and labour market policy in Europe during the crisis (pp. 321-394). Bruxelas: ETUI.

Visser, J. (1995). Trade unions from a comparative perspective. Em J. Van Ruysseveldt, R. Huiskam, e J. Van Hoof (Eds.), Comparative industrial \& employment relations (pp. 37-67). Londres: Sage.

Data de submissão: 14/05/2019 | Data de aceitação: 04/10/2019 